\title{
Autophagy in Human T-Cell Leukemia Virus Type 1 (HTLV-1) Induced Leukemia
}

\begin{abstract}
Nicolás Ducasa ${ }^{1}$, Daniel Grasso ${ }^{2,3}$, Paula Benencio ${ }^{1}$, Daniela L. Papademetrio ${ }^{3,4}$, Mirna Biglione ${ }^{1}$, Fatah Kashanchi ${ }^{5}$, Carolina Berini ${ }^{1 \dagger}$ and Maria Noé Garcia ${ }^{3,4+}$

1 Instituto de Investigaciones Biomédicas en Retrovirus y SIDA (INBIRS), CONICET- Universidad de Buenos Aires, Buenos Aires, Argentina, ${ }^{2}$ Cátedra de Fisiopatología, Facultad de Farmacia y Bioquímica, Universidad de Buenos Aires, Buenos Aires, Argentina, ${ }^{3}$ Consejo Nacional de Investigaciones Científicas y Técnicas (CONICET), Instituto de Estudios de la Inmunidad Humoral (IDEHU), Buenos Aires, Argentina, ${ }^{4}$ Cátedra de Inmunología, Facultad de Farmacia y Bioquímica, Universidad de Buenos Aires, Buenos Aires, Argentina, ${ }^{5}$ Laboratory of Molecular Virology, School of Systems Biology, George Mason University, Manassas, VA, United States
\end{abstract}

OPEN ACCESS

Edited by:

César López-Camarillo, Universidad Autónoma de la Ciudad de México, Mexico

Reviewed by: Kazuhiro Morishita, University of Miyazaki, Japan Eloy Andres Perez Yepez, National Cancer Institute, Mexico

*Correspondence: Maria Noé Garcia mn.garcia@docente.ffyb.uba.ar

${ }^{\dagger}$ These authors have contributed equally to this work

Specialty section: This article was submitted to Molecular and Cellular Oncology, a section of the journal Frontiers in Oncology

Received: 14 December 2020 Accepted: 10 March 2021 Published: 31 March 2021

Citation:

Ducasa N, Grasso D, Benencio $P$, Papademetrio DL, Biglione M, Kashanchi F, Berini $C$ and Garcia MN (2021) Autophagy in Human T-Cell Leukemia Virus Type 1 (HTLV-1) Induced Leukemia.

Front. Oncol. 11:641269. doi: 10.3389/fonc.2021.641269
Viruses play an important role in the development of certain human cancers. They are estimated to contribute 16\% to all human cancers. Human T-cell leukemia virus type 1 $(H T L V-1)$ was the first human retrovirus to be discovered and is the etiological agent of adult T-cell leukemia/lymphoma (ATLL), an aggressive T-cell malignancy with poor prognosis. HTLV-1 viral proteins interact with mechanisms and proteins present in host cells for their own benefit, evading the immune system and promoting the establishment of disease. Several viruses manipulate the autophagy pathway to achieve their infective goals, and HTLV-1 is not the exception. HTLV-1 Tax viral protein engages NF- $\mathrm{KB}$ and autophagy pathways prone favoring viral replication and $T$ cell transformation. In this review we focus on describing the relationship of HTLV-1 with the autophagy machinery and its implication in the development of ATLL.

Keywords: HTLV-1, autophagy, T-cell leukemia, NF-кB, tax

\section{INTRODUCTION}

Human T cell leukemia virus type 1 (HTLV-1), was the first human retrovirus discovered (1). It is the etiological agent of an aggressive $\mathrm{T}$ cell malignancy known as adult $\mathrm{T}$ cell leukemia/lymphoma (ATLL) and a neurologic disease named HTLV-1-associated myelopathy/tropical spastic paraparesis (HAM/TSP), other inflammatory syndromes, opportunistic infections, and lung diseases (2). HTLV1 is transmitted through sexual contact, from mother to child (mainly by prolonged breastfeeding) and parenterally $(3,4)$. In 2014, HTLV-1 was included as group 1 human carcinogens by the International Agency for Research on Cancer (IARC) (5). The vast majority of HTLV-1 infected individuals are asymptomatic and around 3-5\% of them will develop ATLL, that usually occurs after a long latency period. It is clinically classified as smoldering, chronic, lymphoma and acute (6). The smoldering and chronic without unfavorable prognostic factors are categorized as indolent ATLL and generally progress slowly. On the contrary, acute, lymphoma and chronic with unfavorable prognostic factors are aggressive forms and patients have a survival of months $(7,8)$. The HTLV1 genome shares the structural features of other retroviruses, but it also has a $\mathrm{pX}$ region which 
encodes regulatory proteins, such as Tax and bZIP factor (HBZ) (9). HBZ and Tax have opposing functions in most transcription pathways, but both proteins play a critical role in HTLV-1 infection as well as in growth and survival of leukemia cells (10).

Autophagy (also known as macroautophagy) is a degradative process for cellular components including macromolecules such as proteins, RNA and even whole organelles (11). Under stress conditions such as cell starvation, inhibition of mTORC1 (mammalian Target of Rapamycin Complex 1) leads the activation of ULK1 (unc-51 Like Autophagy Activating Kinase 1) complex which in turn triggers the autophagosome biogenesis (12). ULK1 activates a complex which includes BECN1 among its members and a PI3KC3 (phosphatidylinositol 3-kinase Class 3). The PI3P (phosphatidylinositol 3-phosphate) generated by this last complex is required for recruitment of further autophagic proteins and the autophagosome formation. Autophagosomes are double membrane vesicles decorated by LC3 protein and, once it is loaded with the cargo, this particular vesicle is carried to fuse with lysosomes where the cargo is eventually degraded (12-15).

Alternatively, autophagosomes can fuse with components of the endosomal system, late endosomes or multivesicular bodies (MVBs) (16). These hybrid compartments, named as amphisomes, have the options of degrading its intravesicular material by fusion with a lysosome or fusing with the plasma membrane $(17,18)$. In the case they fuse with the plasma membrane, their contents are released outside the cell including extracellular vesicles (EVs) $(19,20)$. These small vesicles have recently gained special relevance since they are important intercellular messengers capable of carrying several molecules, proteins, nucleic acid, and even viral components, and yield an effector response in the target cell (21-24). Importantly, exciting new data is supporting the idea of a superlative crosstalk between autophagy and EVs machineries (25-30). Moreover, autophagy can take an antiviral or pro-viral role. It could be expected to degrade intracellular pathogens, but certain viruses have evolved to use the autophagic machinery for their own benefit, increasing viral replication and viral spread (31).

\section{ADULT T-CELL LEUKEMIA/LYMPHOMA}

The adult T-cell leukemia/lymphoma or ATLL is a malignant and aggressive neoplasm as a consequence of HTLV-1 infection. In endemic regions of Japan, ATLL affects about 8.7 persons per 10,000 HTLV-1 infected citizens and, having in mind an annual incidence of 20 million around the world, it is expected a significant number of persons suffering this pathology (32). In Latin America, 1\% of HTLV-1 infected individuals are asymptomatic positive, but in some endemic areas it might reach $10 \%$ (32). It is interesting to know that HTLV-1 infects T cells, B cells, fibroblasts, dendritic cells, and macrophages, though hitherto data show it is only capable of transforming regulatory $\mathrm{T}$ cells which are positive for CD4/CD25 (33). The carcinogenesis induced by HTLV-1 infection possesses a biphasic behavior, with an initiation and a maintenance phases. Epidemiology demonstrates that ATLL onset is observed about the fifth decade in individuals that were infected during the firsts years of life $(34,35)$. This suggests an extensive latency period coincident with the conception that oncogenesis is initiated in a first phase of viral infection and then a second phase where oncogenic properties of transformed cells are maintained $(34,35)$.

HTLV-1 seems to rely on two main proteins for cellular transformation, HBZ and Tax. Data suggests that HBZ is important for viral replication, cellular proliferation and evasion from the immune system $(36,37)$. Then, the major key role of $\mathrm{HBZ}$ in oncogenesis is maintaining the oncogenic phenotype by attenuation of host immune response against leukemic cells and fostering a microenvironment appropriate for HTLV-1 infected cells (38). On the other hand, Tax is the main actor for the $\mathrm{T}$ cells transformation process engaging several cellular pathways (39). This means that Tax appears early during infection and during the long period of latency time, and it is crucial to initiate cellular transformation. Once cells are transformed, HBZ enters in the second phase for maintaining the transformed phenotype. This is also supported by the fact that Tax gradually disappears during that time, to the point of being almost undetectable, contrary to $\mathrm{HBZ}$ whose presence is prominent and ubiquitous in advanced stages of ATLL $(40,41)$.

The central role of Tax in ATLL is highlighted with the observation that impairment of functionality of tax gene impedes $\mathrm{T}$ cells transformation (42). Even more, Tax overexpression provokes a leukemia phenotype in transgenic mouse models (43, 44). This data suggests that Tax is indeed enough for $\mathrm{T}$ cells immortalization. Moreover, the capacity of Tax to induce cell survival, proliferation and bypass tumor suppressor processes such as senescence and apoptosis has been vastly demonstrated (45-50). The powerful property of Tax lies on its ability to activate a myriad of signaling pathways including PI3K/AKT, p53 inhibition, induction of ROS (reactive oxygen species) production and even genome instability by direct DNA damage and impairment of proteins related to DNA repair $(51,52)$. Although, those characteristics are important in Tax-mediated transformation is worthy to mention specially the NF- $\kappa$ B pathway. Tax has the ability to activate both canonical and noncanonical NF- $\mathrm{BB}$ pathways which in turn set up a broad cell survival program (53-55). Taxmediated initial activation of NF- $\kappa \mathrm{B}$ pathways is in such a way that it persists even after Tax expression has disappeared $(52,56)$.

\section{HTLV-1 TAX RELATIONSHIP WITH THE NF-KB PATHWAY}

The NF- $\kappa B$ family of transcription factors is composed of five

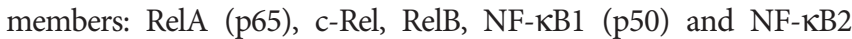
(p52), which can form hetero or homodimeric combinations (57). There are two major pathways for NF- $\kappa B$ activation: the canonical and non-canonical NF- $\kappa \mathrm{B}$ signaling pathways. Canonical NF- $\kappa \mathrm{B}$ signaling is induced upon stimulation by pro-inflammatory cytokines, such as TNF- $\alpha$, IL- $1 \beta$ and IL-6, pathogen-associated molecular patterns (PAMPs) from viruses and bacteria, agonists for the $\mathrm{B}$ or $\mathrm{T}$ cell antigen receptors (BCR or TCR), and chemicals or radiation (58). On the other hand, non-canonical $N F-\kappa B$ signaling pathway is restricted to a subset of TNF family members such as B cell activating factor (BAFF), lymphotoxin $\beta$-(LT $\beta$ ) and CD40L (59). These two pathways of NF- $\kappa \mathrm{B}$ activation differ, not only in the involved receptors, but also, in the implicated molecules and the 
generated response. The induction of the canonical NF- $\kappa \mathrm{B}$ signaling involves a variety of different adaptor molecules to engage the IKK complex which in turn triggers the signaling pathway (60). IKK complex consists of the regulatory subunit IKK $\gamma / \mathrm{NEMO}$, and IKK $\alpha$ and IKK $\beta$, the catalytic ones (61). Once activated, IKK phosphorylates I $\mathrm{K} B s$ subunits ( $\mathrm{I} \kappa \mathrm{B} \alpha, \mathrm{I} \kappa \mathrm{B} \beta$ and $\mathrm{I} \kappa \mathrm{B} \epsilon$ ) inducing the IKBs ubiquitination and proteasomal degradation (62). Then, classical NF- $\mathrm{KB}$ dimers, like p50/RelA and p50/c-Rel, are released from I $\kappa \mathrm{B}$ to enter the nucleus and induce the transcription of target genes (60). This activation of the canonical NF- $\kappa B$ pathway under physiological conditions, induces a rapid but transient transcriptional response $(58,59)$. On the contrary, non-canonical $\mathrm{NF}-\kappa \mathrm{B}$ signaling activation relies on NIK, which in resting cells is constantly degraded by an E3 ligase complex consisting of the E3 ligases c-IAP1/2 and the adaptor TRAF3/TRAF2. Activation of BAFFR, LT $\beta$ R and CD40 provokes inactivation of the TRAF/c-IAP complex and the consequent NIK stabilization. In this situation, NIK phosphorylates IKK, which in turn phosphorylates p100/RelB tagging it for proteasomal processing and the consequent release of
p52/RelB, which translocates to the nucleus. Compared to the canonical way, non-canonical NF- $\kappa \mathrm{B}$ response is delayed, but its transcriptional response is sustained in time $(58,59)$. It has been described the existence of negative regulators of the NF- $\kappa B$ pathway that could be involved in the constitutive activation of NF- $\kappa B$ in ATLL such as TNF- $\alpha$-induced protein 3 (TNFAIP3, A20), Cylindromatosis (CYLD), and NSFL1 cofactor (p47) among others. The implication of any of these negative regulators of the $\mathrm{NF}-\kappa \mathrm{B}$ pathway could be of extreme importance in the persistence of its activation (63-65).

In HTLV-1 infection, Tax persistently activates both canonical and non-canonical NF- $\kappa \mathrm{B}$ pathways which are required for cell survival and $\mathrm{T}$ lymphocyte transformation $(66,67)$. Indeed, a persistent NF- $\mathrm{KB}$ activity is observed in HTLV-1 transformed cell lines (54). By intervention at different levels, Tax ensures the NF- $\mathrm{KB}$ pathway activation without external signals. HTLV-1 Tax interacts with TAK1binding protein 2 (TAB-2) activating MEKK1 and TAK1 which in turn activate the IKK complex $(68,69)$ (Figure 1).

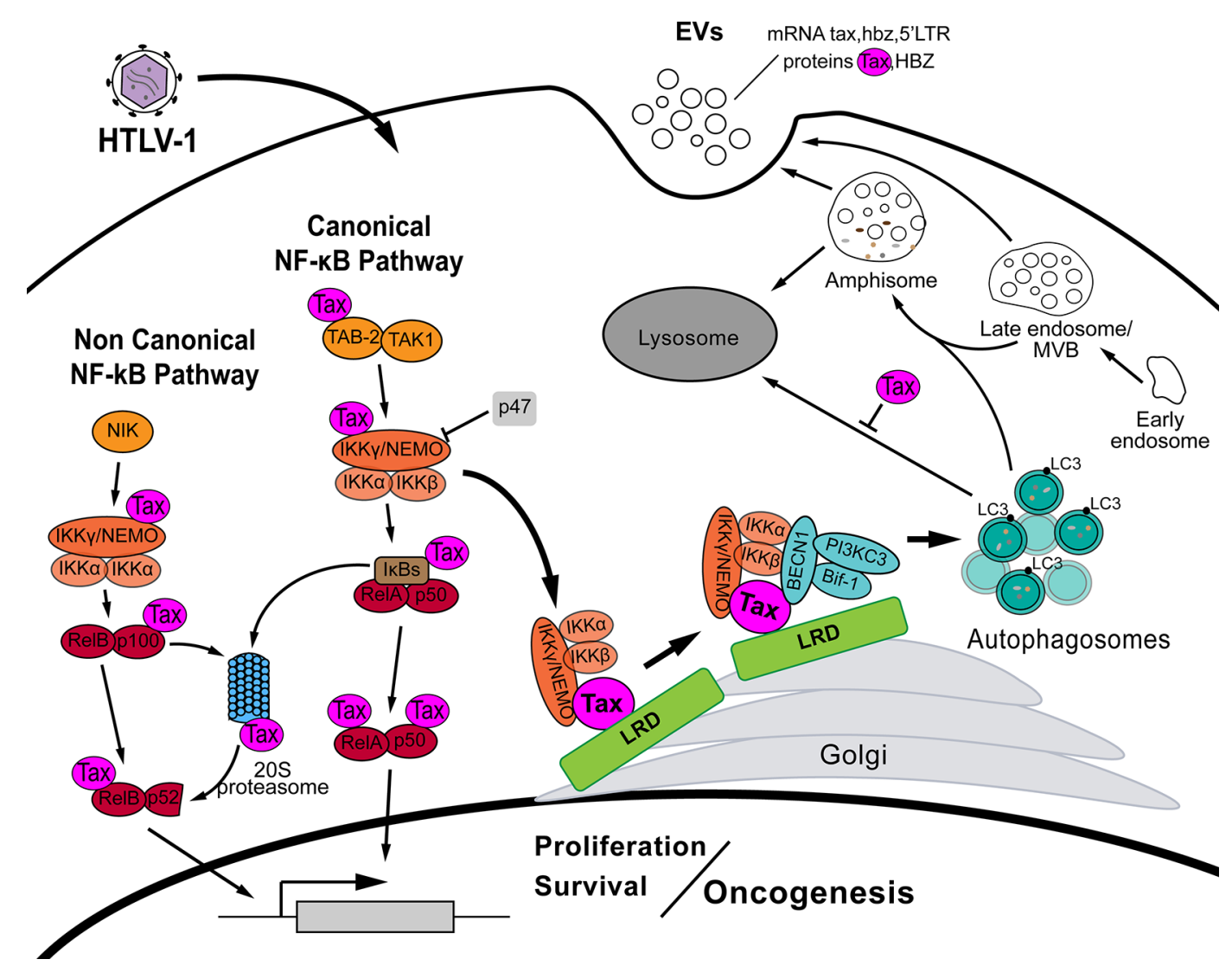

FIGURE 1 | In HTLV-1 infection, the viral protein Tax interferes at several steps of both canonical and noncanonical NF-kB pathway in order to activate it, inducing cell survival and proliferation, and eventually resulting in oncogenesis. By interaction with IKK $\gamma / \mathrm{NEMO}$, Tax recruits and activates IKK complex (IKK $\gamma / \mathrm{NEMO}$, IKK $\alpha$, IKK $\beta$ ) in lipid raft domains (LRD) on the Golgi. After IKK activation, Tax recruits the autophagy proteins BECN1, Bif-1 and the PI3KC3 complex through its direct interaction with BECN1, which in turn binds also with $\mathbb{I K K} \alpha$, IKK $\beta$. Then, Tax deregulates the autophagy pathway fostering autophagosomes biogenesis but, at the same time, blocking the autophagosome-lysosome fusion. Autophagosomes accumulation enhances HTLV-1 replication. Moreover, recent data suggest a crosstalk between autophagic and extracellular vesicles (EVs) biogenesis pathways. EVs from HTLV-1 infected cells bearing the viral proteins Tax and HBZ among some host proteins, and transcriptional mRNA of Tax, HBZ and 5'LTR has been reported. 
The direct association of Tax with IKK $\gamma /$ NEMO in the lipid raft domains (LRD) localized on Golgi is key for Tax goals (70-73). This Tax-IKK $\gamma /$ NEMO interaction recruits the whole IKK complex and this action is indispensable for its activation (Figure 1) (74-76). Moreover, the resulting degradation of $\mathrm{I} \kappa \mathrm{Bs}$ and consequent release of NF- $\kappa \mathrm{B}$ transcription factor subunits are further enhanced by Tax direct interaction with IкBs and 20S proteasome $(54,77)$ (Figure 1). On the other hand, Tax also interacts with IKK $\gamma / \mathrm{NEMO}$ and p100 to induce the proteasome-mediated processing of this last in order to activate the non-canonical NF- $\kappa \mathrm{B}$ pathway $(55,78-82)$. These data are supported by the fact that IKK is persistently activated in primary ATLL and HTLV-1 transformed cells $(54,77)$. The deep involvement of Tax with the NF- $\kappa \mathrm{B}$ pathway is justified by the fact that the activity of this pathway is indispensable for $\mathrm{T}$ cell transformation and the maintenance of the leukemic phenotype $(81,83)$.

\section{HTLV-1 TAX DEREGULATION OF AUTOPHAGY}

The fight between cells and viruses came from a constant competitive evolution. Cells have developed several strategies against viral infections and autophagy is into their toolkit repertory. For instance, xenophagy and virophagy are two types of selective autophagy that are activated in order to clear intracellular pathogens $(84,85)$. Xenophagy leads cells to microorganisms recognition, including viruses, to target them towards lysosome, through the autophagy machinery for degradation by the lysosomal hydrolases (84). In a similar way, virophagy tags specific viral components to be degraded by the autophagy flux (86). Nevertheless, viruses also have evolved to evade those strategies and indeed use autophagy machinery for their own benefit (87). In dendritic cells, one strategy of human immunodeficiency virus (HIV-1) is enhancing mTORC1 activation which in turn inhibits the autophagy pathway (88). Another way, used by herpes simplex virus type 1 (HSV-1), is to produce a specific viral protein that suppresses autophagy by its binding to BECN1, which is essential for autophagosome biogenesis initiation (89). Furthermore, most RNA viruses such as hepatitis $\mathrm{C}$ virus (HCV) induce autophagy flux to use the double membrane of autophagosome vesicles to hide themselves and, in fact proliferate and come out from the host cell $(87,90$, 91). All in all, viruses have developed several strategies with the goal of modifying autophagy in each step, avoiding cellular defensive mechanisms and promoting their proliferation.

It is clear that HTLV-1 infection induces cytoplasmic autophagosomes accumulation and indeed this event increases viral particles production, measured by the viral capsid protein p19 (92). The single transfection of Tax in HeLa and Jurkat cells is enough to accumulate cytoplasmic LC3 positive dots (58). Interestingly, Tax co-localizes with cytoplasmic LC3 puncta but its capacity to accumulate autophagosomes is highly increased when cells are transfected with a Tax targeted by myristoylation to LRDs (83). Worth to note, HTLV-1 capacity to increase cytoplasmic autophagosomes relies also on Tax ability to activate the NF- $\kappa B$ pathway (92). For instance, a mutated Tax without the ability to activate IKK complex is also unable to induce autophagy $(83,93)$. Besides, impairment of any member of the IKK complex, by abolition of the catalytic activity of IKK $\alpha$ or IKK $\beta$, or the knockdown of IKK $\gamma / \mathrm{NEMO}$, decreases the cytoplasmic LC3 positive autophagosomes (83). As commented above, Tax activates the IKK complex by recruiting IKK $\gamma /$ NEMO, and the IKK complex, to the LRD located at the Golgi $(71,73)$. Additionally, in those LRD, Tax recruits BECN1 and Bif-1, and indeed there is an interaction with $\operatorname{PI3KC3}(56,83)$. All those proteins belong to the autophagy PI3KC3 complex, the first structural complex of the autophagosome biogenesis (94). In Tax-immortalized T cells Tax co-precipitates with BECN1 and PI3KC3 but not with UVRAG which form with BECN1 another complex related to the autophagosome maturation $(95,96)$. Without BECN1, Tax is unable to co-precipitated PI3KC3 suggesting that the interaction is through BECN1. Moreover, the sequence of BECN1 that goes from aminoacids 250 to 300 is implicated in the BECN1-Tax interaction (96). Worthy, Taxmediated recruitment and subsequent activation of IKK complex in the LRDs is a prerequisite to further recruitment of BECN1 and Bif- 1 forcing the activation of those autophagy proteins to trigger the autophagosomes biogenesis. This process seems to be exclusive of HTLV-1 infected cells because the co-distribution in LRDs of IKK complex with BECN1 and Bif-1 is only observed in Tax expressing cells (83). Furthermore, the entire IKK complex is key in this Tax-mediated autophagy dysregulation since Tax does not colocalizes in the LRD in absent of IKK $\gamma / \mathrm{NEMO}$ and depletion or impairment of any of the three IKK complex members impedes BECN1 and Bif-1 recruitment to the LRD. The importance of this recruitment is highlighted by the fact that myristoylation of either BECN1 or Bif- 1 to target them towards the LRDs induces autophagy (83). It is important to consider the key role that this function of Tax over autophagy seems to have for HTLV-1 infection. Wang and colleagues described how Taxmediated autophagy provides to infected cells resistance to cell death and, in fact, they suggest to explore autophagy inhibition as a possible treatment against HTLV-1 infection (93).

The relationship between HTLV-1 infection and the autophagy pathway is intricate and the roles of Tax/IKK over the autophagy proteins go in both directions. BECN1 is needed to maintain NF-kB and STAT3 activity in HTLV-1 infected cells (96). STAT3 cooperates with NF- $\mathrm{KB}$ in HTLV-1 infected cells. When silencing BECN1, in HTLV-1 transformed cells, a decreased NF- $\mathrm{KB}$ and STAT3 activity as well as an impairment in cellular growth is observed (96). Furthermore, PI3KC3 or BECN1 depletion significantly slows the proliferation of HTLV-1 infected T lymphocytes (83). Co-precipitation experiments show that BECN1 interacts directly with the catalytic subunits of IKK complex (i.e. IKK $\alpha$ and IKK $\beta$ ) through its C-terminal 150 amino acids region. Neither IKK $\alpha$ nor IKK $\beta$ alone can co-precipitate BECN1 and the PI3KC3 complex suggesting that both are indispensable for the interaction (60). Altogether, in the LRDs Tax recruits the IKK complex, by its interaction with IKK $\gamma /$ NEMO, and the autophagy PI3KC3 complex by its interaction 
with BECN1. In that context BECN1 interacts with IKK $\alpha$ and IKK $\beta$ and it might suggest that LRDs function as a platform where Tax engages the NF-kB and autophagy pathways by the local interaction of Tax, BECN1 and IKK complex (Figure 1). Furthermore, as the autophagy is required for the maintenance of NF- $\kappa B$ activity and the LRD recruitment and activation of IKK is needed for Tax-mediated autophagosomes biogenesis, it is logical to speculate about a positive feedback loop between NF$\kappa \mathrm{B}$ and autophagy pathways in HTLV-1 infection (Figure 1).

Beyond all above comments, HTLV-1 possesses other goals for autophagy deregulation. The p47 protein was recently found in an attempt to find IKK $\gamma / \mathrm{NEMO}$ interactors. Interestingly, p47 is found highly decreased in HTLV-1 infected cells and in cells from ATLL patients (97). Among its different functions, p47 with its UBA domain is related to degradation of ubiquitinated proteins $(98,99)$. In CD4+ $\mathrm{T}$ lymphocytes, $\mathrm{p} 47$ recognizes ubiquitinated IKK $\gamma / \mathrm{NEMO}$ and induces its lysosomal degradation since lysosomal inhibitor but not MG132 (proteasome inhibitor) restore the IKK $\gamma / \mathrm{NEMO}$ levels (97). In this way, p47 negatively regulates IKK $\gamma / \mathrm{NEMO}$ independently of the other two known regulators of the IKK complex, A20 and CYLD $(97,100)$. Worth to note, shRNA-mediated depletion of p47 significantly potentiates I $\mathrm{B} \alpha$ phosphorylation induced by transfection of Tax in HeLa cells (97). This means that p47 opposes the action of Tax over the NF- $\kappa \mathrm{B}$ pathway. In fact, in coprecipitation assay $\mathrm{p} 47$ is unable to precipitate IKK $\gamma / \mathrm{NEMO}$ in presence of Tax suggesting that Tax disrupts the $\mathrm{p} 47$ binding to IKK $\gamma / \mathrm{NEMO}$. The regulation of $\mathrm{p} 47$ seems to be mediated by its stability since cells from patients with the acute type of ATLL the expression of $\mathrm{p} 47$ is similar to uninfected CD4+ T lymphocytes but the amount of $\mathrm{p} 47$ protein is significantly lower (65). This degradation of $\mathrm{p} 47$ is avoided upon lysosomal inhibition but not with MG132. Moreover, in MEFs $\operatorname{Atg} 5^{+/+}$the induction of autophagy by starvation reduces the levels of p47 in stark contrast to $\operatorname{Atg} 5^{-/-}$MEFs where the lack of autophagy does not perturb p47 levels upon cell starvation. Finally, similar results were obtained in HTLV-1 infected cells where shRNA-mediated depletion of ATG5 increased the amount of p47, and concomitantly a decrease in IKK $\gamma / \mathrm{NEMO}$, phosphorylated $\mathrm{I} \kappa \mathrm{B} \alpha$ and even CADM1 (which is a receptor dependent on NF- $\kappa B$ activity) was detected (65). All these data confirm the degradation of $\mathrm{p} 47$ by the autophagy pathway and give an additional reason for Tax-mediated deregulation of the autophagy pathway (Figure 1).

The Tax-mediated deregulation of autophagy by Tax/BECN1/ IKK in the LRDs is completed with its effects on late steps of autophagosome maturation. Data shows that inhibition of autophagosome-lysosome fusion, by means of bafilomycin A1, improves Tax stability suggesting that Tax could be degraded into the lysosome through the autophagy pathway (92). In consequence, they proved that Tax inhibits the fusion of those degradative vesicles (92). Then, HTLV-1 Tax exerts a deep interference in the autophagy pathway fostering autophagosomes biogenesis but, at the same time, inhibiting the autophagosomelysosome fusion (Figure 1). Additionally, new points of contacts between autophagy and HTLV-1 Tax are still being described such as the case of SQSTM-1/p62. In MEFs and HEK293T cells, but not in Jurkat cells, depletion of SQSTM-1/p62 impair the Taxmediated NF- $\mathrm{KB}$ activity. Indeed, SQSTM-1/p62 directly interacts with Tax in the Tax/IKK complex located in Golgiassociated structures (101). SQSTM-1/p62 is an autophagy receptor with domains for recognition of ubiquitin chains and LC3 to canalize cargoes towards the autophagy-mediated degradation $(102,103)$. Similar data is obtained with Optineurin, another autophagy selective receptor, but interestingly in both cases Tax interaction with those proteins seems to be related to Tax-mediated NF- $\kappa B$ activation and not with Tax degradation (101, 104). By the side of HBZ, it negatively regulates the autophagy pathway. In cytoplasm, HBZ associates and inhibits GADD34 which has been demonstrated to be a mTOR inhibitor. Then, HBZ enhances mTOR activity probably for allowing its anabolic functions, though mTOR inhibits the autophagy triggering and in consequence HBZ indirectly inhibits the autophagy pathway $(105,106)$. This is interesting because it might be related to the strategy used by Tax to induce autophagy that is going directly to BECN1/PI3KC3 complex in a manner independent of mTOR activity status. All in all, these data demonstrate that we are not yet watching the whole panorama. Future work would shed light about the complex mechanisms in Tax-autophagy close relationship and whether it includes other autophagy related processes such as selective autophagy, noncanonical forms of autophagy, etc.

Going even further, it has been demonstrated that a constitutively activated IKK complex induces autophagy in vitro and in vivo (107). IKK is implicated in early carcinogenesis inducing autophagy in several tumors in order to cope with the stress related to tumor microenvironment (108). IKK $\beta$ seems to be crucial in this intricate mechanism since this molecule transactivates BECN1 to induce autophagy (109). With very interesting data, Peng and colleagues show that IKK $\beta$ induces accumulation of autophagosomes, but at the same time enhances the fusion of those autophagic vesicles with the MVBs, resulting in amphisomes (110). They also observed the IKK $\beta$-mediated driving of amphisomes toward the plasma membrane with the consequent release of small extracellular vesicles (EVs) which are positive for the autophagic proteins LC3 and SQSTM-1/p62 (110). Importantly, Tax has recently been found in EVs from HTLV-1 infected T cell lines (111). Moreover, those EVs bear the viral proteins Tax and HBZ among some host proteins, and transcriptional mRNA of Tax, HBZ and 5'LTR (Figure 1) (111). The incubation of those EVs with uninfected cell cultures (CTLL-2 and PBMC) increases survival under stress conditions $(111,112)$. This was further confirmed in EVs from ATLL patients derived leukemia cells where Tax was also detected (113). In the same work, EVs purified from ATLL cell line HUT-102 were taken up by bone marrow mesenchymal stem cells (MSC) with the consequent activation of NF- $\mathrm{KB}$ pathway, observable morphological changes, proliferation, activation of a migratory phenotype and presence of angiogenic markers (Figure 1) (113). Putting together the effect of IKK $\beta$ over the autophagy pathway and the release of EVs with presence of EVs containing Tax from infected cells and 
ATLL patients cells it is not difficult to speculate that both events might be connected, though it needs to be confirmed. For sure, these results broaden the views about the possible roles of Tax, and/or other HTLV-1 proteins, regarding all these pathways. Finally, we are just observing the tip of the iceberg about HTLV1 , autophagy, and their relationship in the development of ATLL.

\section{CONCLUSIONS AND PERSPECTIVES}

Most viruses have developed different strategies to overcome cell defenses over evolution, and even more, to use those cellular mechanisms for their own viral cycle. Autophagy is an important homeostatic cellular process and as such it has an antiviral program of action like virophagy and xenophagy. Indeed, HTLV-1 virus induces autophagy to foster viral production. Tax protein seems to be the wild card weapon of HTLV-1, which is able to orchestrate most of the viral action to success in its infective attempt. In the same movement, Tax engages the autophagy and the NF- $\mathrm{KB}$ pathways in such a way that it enough to produce the oncogenic transformation of the cell and, indeed, go on even when Tax is not more detectable. The recent results around IKK, autophagy, the vesicular trafficking and the EVs carrying Tax let us imagine that this is just the beginning in our comprehension of this intricate process. Finally, during

\section{REFERENCES}

1. Gessain A, Cassar O. Epidemiological Aspects and World Distribution of HTLV-1 Infection. Front Microbiol (2012) 3:388. doi: 10.3389/ fmicb.2012.00388

2. Gonçalves DU, Proietti FA, Ribas JGR, Araújo MG, Pinheiro SR, Guedes $\mathrm{AC}$, et al. Epidemiology, treatment, and prevention of human T-cell leukemia virus type 1-associated diseases. Clin Microbiol Rev (2010) 23:577-89. doi: 10.1128/CMR.00063-09

3. Futsch N, Mahieux R, Dutartre H. HTLV-1, the Other Pathogenic Yet Neglected Human Retrovirus: From Transmission to Therapeutic Treatment. Viruses (2017) 10:1. doi: 10.3390/v10010001

4. Matsuoka M, Jeang K-T. Human T-cell leukaemia virus type 1 (HTLV-1) infectivity and cellular transformation. Nat Rev Cancer (2007) 7:270-80. doi: $10.1038 / \mathrm{nrc} 2111$

5. Chen C-J, Hsu W-L, Yang H-I, Lee M-H, Chen H-C, Chien Y-C, et al. Epidemiology of virus infection and human cancer. Recent Results Cancer Res (2014) 193:11-32. doi: 10.1007/978-3-642-38965-8_2

6. Tagaya Y, Matsuoka M, Gallo R. 40 years of the human T-cell leukemia virus: past, present, and future. version 1; peer review: 2 approved. F1000Res (2019) 8:228. doi: 10.12688/f1000research.17479.1

7. Shimoyama M. members of The Lymphoma Study Group (1984-87)*. Diagnostic criteria and classification of clinical subtypes of adult T-cell leukaemia-lymphoma. Br J Haematol (1991) 79:428-37. doi: 10.1111/j.13652141.1991.tb08051.x

8. Tsukasaki K, Hermine O, Bazarbachi A, Ratner L, Ramos JC, Harrington W, et al. Definition, prognostic factors, treatment, and response criteria of adult T-cell leukemia-lymphoma: a proposal from an international consensus meeting. J Clin Oncol (2009) 27:453-9. doi: 10.1200/JCO.2008.18.2428

9. Bangham CRM. Human T cell leukemia virus type 1: persistence and pathogenesis. Annu Rev Immunol (2018) 36:43-71. doi: 10.1146/annurevimmunol-042617-053222

10. Matsuoka M, Yasunaga J. Human T-cell leukemia virus type 1: replication, proliferation and propagation by Tax and HTLV-1 bZIP factor. Curr Opin Virol (2013) 3:684-91. doi: 10.1016/j.coviro.2013.08.010
HTLV-1infection, Tax is in the middle of a complex crossroad that includes inflammatory signal pathways, apoptosis, autophagy, and intercellular communication, that could be the key to uncover its oncogenic transformation ability.

\section{AUTHOR CONTRIBUTIONS}

$\mathrm{CB}, \mathrm{DG}$, and MG conceived the ideas. ND, DG, $\mathrm{CB}$, and MG collected literature resources. DG and MG wrote the original draft. $\mathrm{PB}, \mathrm{MB}$, and FK reviewed manuscript. ND, DP, CB, DG, and MG reviewed and edited the manuscript. All authors contributed to the article and approved the submitted version.

\section{FUNDING}

This work was partially supported by UBACYT-UBA( $20020190200047 \mathrm{BA}$ ) (DLP), UBACYT - UBA (20020190200293BA) (CB), PICT 2015-1105 - ANPCyT (MNG), PICT 2018-02220 - ANPCyT (DG), PICT 2019-00736 - ANPCyT (DP) and PICT 2019-00433 - ANPCyT (CB). The authors thank the University of Buenos Aires and the National Council for Scientific and Technological Research (CONICET) for the facilities to carry out our work every day.

11. Mizushima N, Levine B, Cuervo AM, Klionsky DJ. Autophagy fights disease through cellular self-digestion. Nature (2008) 451:1069-75. doi: 10.1038/ nature06639

12. Grasso D, Renna FJ, Vaccaro MI. Initial steps in mammalian autophagosome biogenesis. Front Cell Dev Biol (2018) 6:146. doi: 10.3389/ fcell.2018.00146

13. Corona Velazquez AF, Jackson WT. So many roads: the multifaceted regulation of autophagy induction. Mol Cell Biol (2018) 38:1-14. doi: 10.1128/MCB.00303-18

14. Dunn WA. Studies on the mechanisms of autophagy: maturation of the autophagic vacuole. J Cell Biol (1990) 110:1935-45. doi: 10.1083/ jcb.110.6.1935

15. Parzych KR, Klionsky DJ. An overview of autophagy: morphology, mechanism, and regulation. Antioxid Redox Signal (2014) 20:460-73. doi: 10.1089/ars.2013.5371

16. Fader CM, Colombo MI. Autophagy and multivesicular bodies: two closely related partners. Cell Death Differ (2009) 16:70-8. doi: 10.1038/cdd.2008.168

17. Peng X, Yang L, Ma Y, Li Y, Li H. Focus on the morphogenesis, fate and the role in tumor progression of multivesicular bodies. Cell Commun Signal (2020) 18:122. doi: 10.1186/s12964-020-00619-5

18. Buratta S, Tancini B, Sagini K, Delo F, Chiaradia E, Urbanelli L, et al. Lysosomal Exocytosis, Exosome Release and Secretory Autophagy: The Autophagic- and Endo-Lysosomal Systems Go Extracellular. Int J Mol Sci (2020) 21:2576. doi: 10.3390/ijms21072576

19. Kowal J, Tkach M, Théry C. Biogenesis and secretion of exosomes. Curr Opin Cell Biol (2014) 29:116-25. doi: 10.1016/j.ceb.2014.05.004

20. Salimi L, Akbari A, Jabbari N, Mojarad B, Vahhabi A, Szafert S, et al. Synergies in exosomes and autophagy pathways for cellular homeostasis and metastasis of tumor cells. Cell Biosci (2020) 10:64. doi: 10.1186/s13578-02000426-y

21. Isola AL, Chen S. Exosomes: the messengers of health and disease. Curr Neuropharmacol (2017) 15:157-65. doi: 10.2174/1570159x14666160825160421

22. Anderson MR, Kashanchi F, Jacobson S. Exosomes in viral disease. Neurotherapeutics (2016) 13:535-46. doi: 10.1007/s13311-016-0450-6

23. Pegtel DM, Gould SJ. Exosomes. Annu Rev Biochem (2019) 88:487-514. doi: 10.1146/annurev-biochem-013118-111902 
24. Jeppesen DK, Fenix AM, Franklin JL, Higginbotham JN, Zhang Q, Zimmerman LJ, et al. Reassessment of exosome composition. Cell (2019) 177:428-45.e18. doi: 10.1016/j.cell.2019.02.029

25. Savina A, Vidal M, Colombo MI. The exosome pathway in K562 cells is regulated by Rab11. J Cell Sci (2002) 115:2505-15.

26. Savina A, Furlán M, Vidal M, Colombo MI. Exosome release is regulated by a calcium-dependent mechanism in K562 cells. J Biol Chem (2003) 278:20083-90. doi: 10.1074/jbc.M301642200

27. Fader CM, Sánchez D, Furlán M, Colombo MI. Induction of autophagy promotes fusion of multivesicular bodies with autophagic vacuoles in $\mathrm{k} 562$ cells. Traffic (2008) 9:230-50. doi: 10.1111/j.1600-0854.2007.00677.x

28. Fader CM, Sánchez DG, Mestre MB, Colombo MI. TI-VAMP/VAMP7 and VAMP3/cellubrevin: two v-SNARE proteins involved in specific steps of the autophagy/multivesicular body pathways. Biochim Biophys Acta (2009) 1793:1901-16. doi: 10.1016/j.bbamcr.2009.09.011

29. Xu J, Camfield R, Gorski SM. The interplay between exosomes and autophagy - partners in crime. J Cell Sci (2018) 131:jcs215210. doi: $10.1242 /$ jcs. 215210

30. Hessvik NP, Øverbye A, Brech A, Torgersen ML, Jakobsen IS, Sandvig K, et al. PIKfyve inhibition increases exosome release and induces secretory autophagy. Cell Mol Life Sci (2016) 73:4717-37. doi: 10.1007/s00018-0162309-8

31. Kudchodkar SB, Levine B. Viruses and autophagy. Rev Med Virol (2009) 19:359-78. doi: 10.1002/rmv.630

32. Satake M, Yamada Y, Atogami S, Yamaguchi K. The incidence of adult T-cell leukemia/lymphoma among human T-lymphotropic virus type 1 carriers in Japan. Leuk Lymphoma (2015) 56:1806-12. doi: 10.3109/10428194.2014.964700

33. Qayyum S, Choi JK. Adult T-cell leukemia/lymphoma. Arch Pathol Lab Med (2014) 138:282-6. doi: 10.5858/arpa.2012-0379-RS

34. Murphy EL, Hanchard B, Figueroa JP, Gibbs WN, Lofters WS, Campbell M, et al. Modelling the risk of adult T-cell leukemia/lymphoma in persons infected with human T-lymphotropic virus type I. Int J Cancer (1989) 43:250-3. doi: 10.1002/ijc.2910430214

35. Yamaguchi K. Pathogenesis of adult T-cell leukemia from clinical pathologic features. Hum retrovirology: HTLV (1990) 163-70.

36. Tsukasaki K, Tobinai K. Human T-cell lymphotropic virus type I-associated adult T-cell leukemia-lymphoma: new directions in clinical research. Clin Cancer Res (2014) 20:5217-25. doi: 10.1158/1078-0432.CCR-14-0572

37. Tsukasaki K. Adult T-cell leukemia-lymphoma. Hematology (2012) $17 \mathrm{Suppl}$ 1:S32-5. doi: 10.1179/102453312X13336169155330

38. Rodríguez-Zúñiga MJM, Cortez-Franco F, Qujiano-Gomero E. Adult T-Cell Leukemia/Lymphoma. Review of the Literature. Actas Dermosifiliogr (2018) 109:399-407. doi: 10.1016/j.ad.2017.08.014

39. Bangham CRM, Toulza F. Adult T cell leukemia/lymphoma: FoxP3(+) cells and the cell-mediated immune response to HTLV-1. Adv Cancer Res (2011) 111:163-82. doi: 10.1016/B978-0-12-385524-4.00004-0

40. Furukawa Y, Okadome T, Tara M, Niina K, Izumo S, Osame M. Human Tcell lymphotropic virus type-I (HTLV-I)-associated myelopathy/tropical spastic paraparesis with acute type of adult T-cell leukemia. Intern Med (1995) 34:1130-3. doi: 10.2169/internalmedicine.34.1130

41. Furukawa Y, Kubota R, Tara M, Izumo S, Osame M. Existence of escape mutant in HTLV-I tax during the development of adult T-cell leukemia. Blood (2001) 97:987-93. doi: 10.1182/blood.v97.4.987

42. Ratner L, Portis T, Robek M, Harding J, Grossman W. Studies of the immortalizing activity of HTLV type 1 Tax, using an infectious molecular clone and transgenic mice. AIDS Res Hum Retroviruses (2000) 16:1647-51. doi: 10.1089/08892220050193092

43. Nerenberg M, Hinrichs SH, Reynolds RK, Khoury G, Jay G. The tat gene of human T-lymphotropic virus type 1 induces mesenchymal tumors in transgenic mice. Science (1987) 237:1324-9. doi: 10.1126/science.2888190

44. Grossman WJ, Kimata JT, Wong FH, Zutter M, Ley TJ, Ratner L. Development of leukemia in mice transgenic for the tax gene of human T-cell leukemia virus type I. Proc Natl Acad Sci USA (1995) 92:1057-61. doi: 10.1073/pnas.92.4.1057

45. Grassmann R, Berchtold S, Radant I, Alt M, Fleckenstein B, Sodroski JG, et al. Role of human T-cell leukemia virus type $1 \mathrm{X}$ region proteins in immortalization of primary human lymphocytes in culture. J Virol (1992) 66:4570-5. doi: 10.1128/JVI.66.7.4570-4575.1992
46. Franchini G. Molecular mechanisms of human T-cell leukemia/ lymphotropic virus type I infection. Blood (1995) 86:3619-39. doi: 10.1182/blood.V86.10.3619.bloodjournal86103619

47. Yoshida M. Multiple viral strategies of HTLV-1 for dysregulation of cell growth control. Annu Rev Immunol (2001) 19:475-96. doi: 10.1146/ annurev.immunol.19.1.475

48. Wang W, Zhou J, Shi J, Zhang Y, Liu S, Liu Y, et al. Human T-cell leukemia virus type 1 Tax-deregulated autophagy pathway and c-FLIP expression contribute to resistance against death receptor-mediated apoptosis. J Virol (2014) 88:2786-98. doi: 10.1128/JVI.03025-13

49. Bangham CRM, Matsuoka M. Human T-cell leukaemia virus type 1: parasitism and pathogenesis. Philos Trans R Soc Lond B Biol Sci (2017) 372:20160272. doi: 10.1098/rstb.2016.0272

50. Karimi M, Mohammadi H, Hemmatzadeh M, Mohammadi A, Rafatpanah H, Baradaran B. Role of the HTLV-1 viral factors in the induction of apoptosis. BioMed Pharmacother (2017) 85:334-47. doi: 10.1016/ j.biopha.2016.11.034

51. Cereseto A, Washington Parks R, Rivadeneira E, Franchini G. Limiting amounts of p27Kip1 correlates with constitutive activation of cyclin E-CDK2 complex in HTLV-I-transformed T-cells. Oncogene (1999) 18:2441-50. doi: 10.1038/sj.onc. 1202567

52. Marriott SJ, Semmes OJ. Impact of HTLV-I Tax on cell cycle progression and the cellular DNA damage repair response. Oncogene (2005) 24:5986-95. doi: 10.1038/sj.onc.1208976

53. Fochi S, Mutascio S, Bertazzoni U, Zipeto D, Romanelli MG. HTLV Deregulation of the NF- $\kappa B$ Pathway: An Update on Tax and Antisense Proteins Role. Front Microbiol (2018) 9:285. doi: 10.3389/fmicb.2018.00285

54. Sun SC, Elwood J, Béraud C, Greene WC. Human T-cell leukemia virus type I Tax activation of NF-kappa B/Rel involves phosphorylation and degradation of I kappa B alpha and RelA (p65)-mediated induction of the c-rel gene. Mol Cell Biol (1994) 14:7377-84. doi: 10.1128/mcb.14.11.7377

55. Higuchi M, Tsubata C, Kondo R, Yoshida S, Takahashi M, Oie M, et al. Cooperation of NF-kappaB2/p100 activation and the PDZ domain binding motif signal in human T-cell leukemia virus type 1 (HTLV-1) Taxl but not HTLV-2 Tax2 is crucial for interleukin-2-independent growth transformation of a T-cell line. J Virol (2007) 81:11900-7. doi: 10.1128/ JVI.00532-07

56. Cheng H, Ren T, Sun S. New insight into the oncogenic mechanism of the retroviral oncoprotein Tax. Protein Cell (2012) 3:581-9. doi: 10.1007/ s13238-012-2047-0

57. Oeckinghaus A, Ghosh S. The NF-kappaB family of transcription factors and its regulation. Cold Spring Harb Perspect Biol (2009) 1:a000034. doi: 10.1101/cshperspect.a000034

58. Krappmann D, Vincendeau M. Mechanisms of NF- $\mathrm{KB}$ deregulation in lymphoid malignancies. Semin Cancer Biol (2016) 39:3-14. doi: 10.1016/ j.semcancer.2016.05.002

59. Sun S-C. The noncanonical NF- $\kappa B$ pathway. Immunol Rev (2012) 246:12540. doi: 10.1111/j.1600-065X.2011.01088.x

60. Hayden MS, Ghosh S. Shared principles in NF-kappaB signaling. Cell (2008) 132:344-62. doi: 10.1016/j.cell.2008.01.020

61. Israël A. The IKK complex, a central regulator of NF-kappaB activation. Cold Spring Harb Perspect Biol (2010) 2:a000158. doi: 10.1101/ cshperspect.a000158

62. Liu F, Xia Y, Parker AS, Verma IM. IKK biology. Immunol Rev (2012) 246:239-53. doi: 10.1111/j.1600-065X.2012.01107.x

63. Zhang F, Yang L, Li Y. The role of A20 in the pathogenesis of lymphocytic malignancy. Cancer Cell Int (2012) 12:44. doi: 10.1186/1475-2867-12-44

64. Massoumi R. CYLD: a deubiquitination enzyme with multiple roles in cancer. Future Oncol (2011) 7:285-97. doi: 10.2217/fon.10.187

65. Sarkar B, Nishikata I, Nakahata S, Ichikawa T, Shiraga T, Saha HR, et al. Degradation of $\mathrm{p} 47$ by autophagy contributes to CADM1 overexpression in ATLL cells through the activation of NF-KB. Sci Rep (2019) 9:3491. doi: 10.1038/s41598-019-39424-7

66. Sun SC, Ballard DW. Persistent activation of NF-kappaB by the tax transforming protein of HTLV-1: hijacking cellular IkappaB kinases. Oncogene (1999) 18:6948-58. doi: 10.1038/sj.onc.1203220

67. Pise-Masison CA, Choi KS, Radonovich M, Dittmer J, Kim SJ, Brady JN. Inhibition of p53 transactivation function by the human T-cell lymphotropic 
virus type 1 Tax protein. J Virol (1998) 72:1165-70. doi: 10.1128/ JVI.72.2.1165-1170.1998

68. Yin MJ, Christerson LB, Yamamoto Y, Kwak YT, Xu S, Mercurio F, et al. HTLV-I Tax protein binds to MEKK1 to stimulate IkappaB kinase activity and NF-kappaB activation. Cell (1998) 93:875-84. doi: 10.1016/s0092-8674 (00)81447-6

69. Wu X, Sun S-C. Retroviral oncoprotein Tax deregulates NF-kappaB by activating Tak1 and mediating the physical association of Tak1-IKK. EMBO Rep (2007) 8:510-5. doi: 10.1038/sj.embor.7400931

70. Nejmeddine M, Barnard AL, Tanaka Y, Taylor GP, Bangham CRM. Human T-lymphotropic virus, type 1 , tax protein triggers microtubule reorientation in the virological synapse. J Biol Chem (2005) 280:29653-60. doi: 10.1074/ jbc.M502639200

71. Harhaj NS, Sun S-C, Harhaj EW. Activation of NF-kappa B by the human T cell leukemia virus type I Tax oncoprotein is associated with ubiquitindependent relocalization of I kappa B kinase. J Biol Chem (2007) 282:418592. doi: $10.1074 /$ jbc.M611031200

72. Lamsoul I, Lodewick J, Lebrun S, Brasseur R, Burny A, Gaynor RB, et al. Exclusive ubiquitination and sumoylation on overlapping lysine residues mediate NF-kappaB activation by the human T-cell leukemia virus tax oncoprotein. Mol Cell Biol (2005) 25:10391-406. doi: 10.1128/ MCB.25.23.10391-10406.2005

73. Huang J, Ren T, Guan H, Jiang Y, Cheng H. HTLV-1 Tax is a critical lipid raft modulator that hijacks IkappaB kinases to the microdomains for persistent activation of NF-kappaB. J Biol Chem (2009) 284:6208-17. doi: 10.1074/jbc.M806390200

74. Harhaj EW, Sun SC. IKKgamma serves as a docking subunit of the IkappaB kinase (IKK) and mediates interaction of IKK with the human T-cell leukemia virus Tax protein. J Biol Chem (1999) 274:22911-4. doi: 10.1074/ jbc.274.33.22911

75. Li ZW, Chu W, Hu Y, Delhase M, Deerinck T, Ellisman M, et al. The IKKbeta subunit of IkappaB kinase (IKK) is essential for nuclear factor kappaB activation and prevention of apoptosis. J Exp Med (1999) 189:183945. doi: $10.1084 /$ jem.189.11.1839

76. Jin DY, Giordano V, Kibler KV, Nakano H, Jeang KT. Role of adapter function in oncoprotein-mediated activation of NF-kappaB. Human T-cell leukemia virus type I Tax interacts directly with IkappaB kinase gamma. J Biol Chem (1999) 274:17402-5. doi: 10.1074/jbc.274.25.17402

77. Mori N, Fujii M, Ikeda S, Yamada Y, Tomonaga M, Ballard DW, et al. Constitutive Activation of NF- $\mathrm{KB}$ in Primary Adult T-Cell Leukemia Cells. Blood (1999) 93:2360-8. doi: 10.1097/00042560-199904010-00027

78. Béraud C, Sun SC, Ganchi P, Ballard DW, Greene WC. Human T-cell leukemia virus type I Tax associates with and is negatively regulated by the NF-kappa B2 p100 gene product: implications for viral latency. Mol Cell Biol (1994) 14:1374-82. doi: 10.1128/mcb.14.2.1374

79. Uhlik M, Good L, Xiao G, Harhaj EW, Zandi E, Karin M, et al. NF-kappaBinducing kinase and IkappaB kinase participate in human T-cell leukemia virus I Tax-mediated NF-kappaB activation. J Biol Chem (1998) 273:211326. doi: $10.1074 / \mathrm{jbc} .273 .33 .21132$

80. Xiao G, Harhaj EW, Sun SC. NF-kappaB-inducing kinase regulates the processing of NF-kappaB2 p100. Mol Cell (2001) 7:401-9. doi: 10.1016/ s1097-2765(01)00187-3

81. Harhaj EW, Giam C-Z. NF- $\mathrm{KB}$ signaling mechanisms in HTLV-1-induced adult T-cell leukemia/lymphoma. FEBS J (2018) 285:3324-36. doi: 10.1111/febs.14492

82. Fochi S, Ciminale V, Trabetti E, Bertazzoni U, D’Agostino DM, Zipeto D, et al. NF- $\mathrm{kB}$ and MicroRNA Deregulation Mediated by HTLV-1 Tax and HBZ. Pathogens (2019) 8:290. doi: 10.3390/pathogens8040290

83. Ren T, Takahashi Y, Liu X, Loughran TP, Sun SC, Wang HG, et al. HTLV-1 Tax deregulates autophagy by recruiting autophagic molecules into lipid raft microdomains. Oncogene (2015) 34:334-45. doi: 10.1038/onc.2013.552

84. Levine B. Eating oneself and uninvited guests: autophagy-related pathways in cellular defense. Cell (2005) 120:159-62. doi: 10.1016/j.cell.2005.01.005

85. Lee J-S, Li Q, Lee J-Y, Lee S-H, Jeong JH, Lee H-R, et al. FLIP-mediated autophagy regulation in cell death control. Nat Cell Biol (2009) 11:1355-62. doi: $10.1038 /$ ncb 1980

86. Orvedahl A, Sumpter R, Xiao G, Ng A, Zou Z, Tang Y, et al. Image-based genome-wide siRNA screen identifies selective autophagy factors. Nature (2011) 480:113-7. doi: 10.1038/nature10546
87. Mao J, Lin E, He L, Yu J, Tan P, Zhou Y. Autophagy and viral infection. Adv Exp Med Biol (2019) 1209:55-78. doi: 10.1007/978-981-15-0606-2_5

88. Blanchet FP, Moris A, Nikolic DS, Lehmann M, Cardinaud S, Stalder R, et al. Human immunodeficiency virus-1 inhibition of immunoamphisomes in dendritic cells impairs early innate and adaptive immune responses. Immunity (2010) 32:654-69. doi: 10.1016/j.immuni.2010.04.011

89. Orvedahl A, Alexander D, Tallóczy Z, Sun Q, Wei Y, Zhang W, et al. HSV-1 ICP34.5 confers neurovirulence by targeting the Beclin 1 autophagy protein. Cell Host Microbe (2007) 1:23-35. doi: 10.1016/j.chom.2006.12.001

90. Dreux M, Chisari FV. Autophagy proteins promote hepatitis C virus replication. Autophagy (2009) 5:1224-5. doi: 10.4161/auto.5.8.10219

91. Shrivastava S, Raychoudhuri A, Steele R, Ray R, Ray RB. Knockdown of autophagy enhances the innate immune response in hepatitis $C$ virusinfected hepatocytes. Hepatology (2011) 53:406-14. doi: 10.1002/hep.24073

92. Tang S-W, Chen C-Y, Klase Z, Zane L, Jeang K-T. The cellular autophagy pathway modulates human T-cell leukemia virus type 1 replication. J Virol (2013) 87:1699-707. doi: 10.1128/JVI.02147-12

93. Wang J, Niu Z, Shi Y, Gao C, Wang X, Han J, et al. Bcl-3, induced by Tax and HTLV-1, inhibits NF-KB activation and promotes autophagy. Cell Signal (2013) 25:2797-804. doi: 10.1016/j.cellsig.2013.09.010

94. Takahashi Y, Coppola D, Matsushita N, Cualing HD, Sun M, Sato Y, et al. Bif-1 interacts with Beclin 1 through UVRAG and regulates autophagy and tumorigenesis. Nat Cell Biol (2007) 9:1142-51. doi: 10.1038/ncb1634

95. Ohashi Y, Tremel S, Williams RL. VPS34 complexes from a structural perspective. J Lipid Res (2019) 60:229-41. doi: 10.1194/jlr.R089490

96. Chen L, Liu D, Zhang Y, Zhang H, Cheng H. The autophagy molecule Beclin 1 maintains persistent activity of NF- $\mathrm{KB}$ and Stat 3 in HTLV-1-transformed T lymphocytes. Biochem Biophys Res Commun (2015) 465:739-45. doi: $10.1016 /$ j.bbrc.2015.08.070

97. Shibata Y, Oyama M, Kozuka-Hata H, Han X, Tanaka Y, Gohda J, et al. p47 negatively regulates IKK activation by inducing the lysosomal degradation of polyubiquitinated NEMO. Nat Commun (2012) 3:1061. doi: 10.1038/ ncomms 2068

98. Hartmann-Petersen R, Wallace M, Hofmann K, Koch G, Johnsen AH, Hendil KB, et al. The Ubx2 and Ubx3 cofactors direct Cdc48 activity to proteolytic and nonproteolytic ubiquitin-dependent processes. Curr Biol (2004) 14:824-8. doi: 10.1016/j.cub.2004.04.029

99. Wójcik C, Yano M, DeMartino GN. RNA interference of valosin-containing protein $(\mathrm{VCP} / \mathrm{p} 97)$ reveals multiple cellular roles linked to ubiquitin/ proteasome-dependent proteolysis. J Cell Sci (2004) 117:281-92. doi: $10.1242 /$ jcs.00841

100. Pujari R, Hunte R, Khan WN, Shembade N. A20-mediated negative regulation of canonical NF- $\mathrm{KB}$ signaling pathway. Immunol Res (2013) 57:166-71. doi: 10.1007/s12026-013-8463-2

101. Schwob A, Teruel E, Dubuisson L, Lormières F, Verlhac P, Abudu YP, et al. SQSTM-1/p62 potentiates HTLV-1 Tax-mediated NF- KB activation through its ubiquitin binding function. Sci Rep (2019) 9:16014. doi: 10.1038/s41598019-52408-x

102. Pankiv S, Clausen TH, Lamark T, Brech A, Bruun J-A, Outzen H, et al. p62/ SQSTM1 binds directly to Atg8/LC3 to facilitate degradation of ubiquitinated protein aggregates by autophagy. J Biol Chem (2007) 282:24131-45. doi: 10.1074/jbc.M702824200

103. Svenning S, Johansen T. Selective autophagy. Essays Biochem (2013) 55:7992. doi: $10.1042 / \mathrm{bse} 0550079$

104. Journo C, Filipe J, About F, Chevalier SA, Afonso PV, Brady JN, et al. NRP/ Optineurin Cooperates with TAX1BP1 to potentiate the activation of NFkappaB by human T-lymphotropic virus type 1 tax protein. PloS Pathog (2009) 5:e1000521. doi: 10.1371/journal.ppat.1000521

105. Mukai R, Ohshima T. HTLV-1 HBZ positively regulates the mTOR signaling pathway via inhibition of GADD34 activity in the cytoplasm. Oncogene (2014) 33:2317-28. doi: 10.1038/onc.2013.181

106. Vescovo T, Pagni B, Piacentini M, Fimia GM, Antonioli M. Regulation of autophagy in cells infected with oncogenic human viruses and its impact on cancer development. Front Cell Dev Biol (2020) 8:47. doi: 10.3389/ fcell.2020.00047

107. Criollo A, Senovilla L, Authier H, Maiuri MC, Morselli E, Vitale I, et al. The IKK complex contributes to the induction of autophagy. EMBO J (2010) 29:619-31. doi: 10.1038/emboj.2009.364 
108. Leonardi M, Perna E, Tronnolone S, Colecchia D, Chiariello M. Activated kinase screening identifies the IKBKE oncogene as a positive regulator of autophagy. Autophagy (2019) 15:312-26. doi: 10.1080/15548627.2018.1517855

109. Dikic I, Elazar Z. Mechanism and medical implications of mammalian autophagy. Nat Rev Mol Cell Biol (2018) 19:349-64. doi: 10.1038/s41580018-0003-4

110. Peng X, Yang L, Ma Y, Li X, Yang S, Li Y, et al. IKK $\beta$ activation promotes amphisome formation and extracellular vesicle secretion in tumor cells. Biochim Biophys Acta Mol Cell Res (2021) 1868:118857. doi: 10.1016/ j.bbamcr.2020.118857

111. Jaworski E, Narayanan A, Van Duyne R, Shabbeer-Meyering S, Iordanskiy S, Saifuddin M, et al. Human T-lymphotropic virus type 1-infected cells secrete exosomes that contain Tax protein. J Biol Chem (2014) 289:22284-305. doi: 10.1074/jbc.M114.549659

112. Otaguiri KK, Dos Santos DF, Slavov SN, Depieri LV, Palma PVB, Meirelles FV, et al. TAX-mRNA-Carrying Exosomes from Human T Cell Lymphotropic Virus Type 1-Infected Cells Can Induce Interferon-Gamma
Production In Vitro. AIDS Res Hum Retroviruses (2018) 34:1075-82. doi: 10.1089/AID.2018.0115

113. El-Saghir J, Nassar F, Tawil N, El-Sabban M. ATL-derived exosomes modulate mesenchymal stem cells: potential role in leukemia progression. Retrovirology (2016) 13:73. doi: 10.1186/s12977-016-0307-4

Conflict of Interest: The authors declare that the research was conducted in the absence of any commercial or financial relationships that could be construed as a potential conflict of interest.

Copyright (C) 2021 Ducasa, Grasso, Benencio, Papademetrio, Biglione, Kashanchi, Berini and Garcia. This is an open-access article distributed under the terms of the Creative Commons Attribution License (CC BY). The use, distribution or reproduction in other forums is permitted, provided the original author(s) and the copyright owner(s) are credited and that the original publication in this journal is cited, in accordance with accepted academic practice. No use, distribution or reproduction is permitted which does not comply with these terms. 